\title{
Myc interacts with Max and Miz1 to repress C/EBP $\delta$ promoter activity and gene expression
}

\author{
Junling $\mathrm{Si}^{1,2}$, Xueyan Yu1,2, Yingjie Zhang ${ }^{1,2}$ and James W DeWille*1,2
}

\begin{abstract}
Background: "Loss of function" alterations in CCAAT/Enhancer Binding Protein $\delta$ (C/EBP $\delta$ ) have been reported in a number of human cancers including breast, prostate and cervical cancer, hepatocellular carcinoma and acute myeloid leukemia. C/EBPS gene transcription is induced during cellular quiescence and repressed during active cell cycle progression. C/EBPS exhibits tumor suppressor gene properties including reduced expression in cancer cell lines and tumors and promoter methylation silencing.

We previously reported that C/EBPS expression is inversely correlated with c-Myc (Myc) expression. Aberrant Myc expression is common in cancer and transcriptional repression is a major mechanism of Myc oncogenesis. A number of tumor suppressor genes are targets of Myc transcriptional repression including C/EBPa, p15INK4, p21 CIP1, p27KIP1 and $\mathrm{p} 57^{\mathrm{KIP} 2}$. This study investigated the mechanisms underlying Myc repression of C/EBP $\delta$ expression.

Results: Myc represses C/EBPS promoter activity in nontransformed mammary epithelial cells in a dose-dependent manner that requires Myc Box II, Basic Region and HLH/LZ domains. Chromatin Immunoprecipitation (ChIP) assays demonstrate that Myc, Miz1 and Max are associated with the C/EBP $\delta$ promoter in proliferating cells, when C/EBP $\delta$ expression is repressed. EMSAs demonstrate that Miz1 binds to a 30 bp region (-100 to -70) of the C/EBPS promoter which contains a putative transcription initiator (Inr) element. Miz1 functions exclusively as a repressor of C/EBP $\delta$ promoter activity. Miz1 siRNA expression or expression of a Miz1 binding deficient Myc (MycV394D) construct reduces Myc repression of C/EBPS promoter activity. Max siRNA expression, or expression of a Myc construct lacking the HLH/ LZ (Max interacting) region, also reduces Myc repression of C/EBPS promoter activity. Miz1 and Max siRNA treatments attenuate Myc repression of endogenous C/EBPS expression. Myc Box II interacting proteins RuvBl1 (Pontin, TIP49) and RuvBI2 (Reptin, TIP48) enhances Myc repression of C/EBP $\delta$ promoter activity.

Conclusion: Myc represses C/EBPS expression by associating with the C/EBP $\delta$ proximal promoter as a transient component of a repressive complex that includes Max and Miz1. RuvBl1 and RuvBl2 enhance Myc repression of C/EBP $\delta$ promoter activity. These results identify protein interactions that mediate Myc repression of C/EBPS, and possibly other tumor suppressor genes, and suggest new therapeutic targets to block Myc transcriptional repression and oncogenic function.
\end{abstract}

\section{Background}

CCAAT/Enhancer Binding Protein $(\mathrm{C} / \mathrm{EBP} \delta$ ) is a member of the highly conserved C/EBP family of leucine zipper DNA binding proteins [1-3]. C/EBP $\delta$ gene expression is increased in nontransformed mammary epithelial cells (MECs) in response to $\mathrm{G}_{0}$ growth arrest conditions and IL-6 family cytokine treatment [4-11]. Ectopic C/EBPS expression induces growth arrest of mammary epithelial,

* Correspondence: dewille.1@osu.edu

1 Department of Veterinary Biosciences, Ohio State University College of Veterinary Medicine, Columbus Ohio, 43210, USA

Full list of author information is available at the end of the article prostate and chronic myelogenous leukemia cell lines $[5,12,13]$. Conversely, reducing C/EBP $\delta$ gene expression is associated with delayed growth arrest, genomic instability, impaired contact inhibition, increased cell migration and increased growth in reduced serum media $[5,14]$. In vivo, female C/EBP $\delta$ knockout mice exhibit increased mammary epithelial cell proliferation and mammary gland ductal hyperplasia [15].

"Loss of function" alterations in C/EBP $\delta$ gene expression have been reported in human and experimental cancer. Using Serial Analysis of Gene Expression (SAGE) 
assays Polyak and coworkers demonstrated that C/EBP $\delta$ is down regulated in the progression from normal breast epithelium to advanced breast cancer [16,17]. Other reports have shown that $\mathrm{C} / \mathrm{EBP} \delta$ gene expression is reduced in $\sim 30 \%$ of primary human breast tumors and in primary prostate tumors $[11,18]$. In experimental models, $\mathrm{C} / \mathrm{EBP} \delta$ expression is reduced in carcinogen-induced mammary tumors and in $50 \%$ of mammary tumors isolated from MMTV/c-neu transgenic mice [19,20].

Studies addressing the mechanisms underlying loss of function alterations in C/EBP gene expression demonstrated that the C/EBP $\delta$ gene promoter is silenced by promoter hypermethylation in the SUM-52PE human breast cancer cell line (26/27 CpGs methylated) and by site-specific methylation in primary human breast tumor isolates [11]. C/EBP $\delta$ gene expression is also silenced by promoter hypermethylation in primary cervical cancer and hepatocellular carcinoma (HCC) [21]. In addition to solid tumors, C/EBP $\delta$ gene expression is reduced and the $\mathrm{C} /$ EBP $\delta$ promoter is silenced by hypermethylation in the U937 human lymphoma derived cell line and in $~ 35 \%$ of lymphoma cells isolated from AML patients [22]. Although C/EBP $\delta$ expression is reduced in primary tumors and cancer derived cell lines inactivating mutations in the intronless C/EBP $\delta$ gene are rare [23,24]. This indicates that alterations in regulatory mechanisms that control C/EBP $\delta$ gene expression play a key role in cancerrelated C/EBPS "loss of function" alterations. We used nuclear run-on assays to investigate C/EBP $\delta$ transcriptional regulation and found that $\mathrm{C} / \mathrm{EBP} \delta$ gene transcription is induced $\sim 6$ fold in $G_{0}$ growth arrested nontransformed mammary epithelial cells compared to actively proliferating mammary epithelial cells [6]. These findings demonstrated the importance of transcriptional control of C/EBP $\delta$ gene expression and suggested that alterations in transcriptional activators or repressors would have a major impact on C/EBP $\delta$ expression and cellular growth control.

c-Myc (Myc) is a member of the Myc family of helix loop helix proteins that function in the activation and repression of target gene transcription [25]. Myc expression promotes cell proliferation and Myc over expression has been documented in a wide range of human cancers [25]. The Myc gene is frequently amplified in breast cancer and experimental studies indicate that Myc is a downstream transcriptional effector of ErbB2 receptor tyrosine kinase activation, a signaling pathway that is commonly dysregulated and constitutively active in breast cancer $[26,27]$. Accumulating evidence indicates that transcriptional repression of Myc target genes is a major mechanism in which Myc promotes cell transformation [28]. Myc represses the transcription of key growth control, differentiation and tumor suppressor genes including GAS1, p15 ${ }^{I N K 4}, \mathrm{p} 21^{C I P 1}, \mathrm{p} 27^{K I P 1}, \mathrm{p} 57^{K I P 2}$, growth arrest and DNA damage 34 (GADD34), GADD45, C/EBP $\alpha$ and GADD153 (C/EBPC) [25,28-42].

We previously reported that the C/EBP $\delta$ proximal promoter is in a constitutively "open" chromatin conformation and that the C/EBP $\delta$ proximal promoter is accessible to activating (Sp1, pSTAT3, CREB) and repressive (Myc) transcriptional regulatory factors [43]. Myc repression of $\mathrm{C} / \mathrm{EBP} \delta$ gene transcription may promote mammary tumorigenesis as C/EBP $\delta$ functions as a transcriptional activator of growth arrest, differentiation, apoptosis and inflammation related genes $[3,44]$. Myc repression is mediated by Myc interactions with promoter-bound transcriptional control proteins such as Sp1, Smads and Miz1 [25,44]. In this report, we provide new mechanistic insights into Myc repression of C/EBPS gene expression. We demonstrate that Myc repression of the C/EBP $\delta$ promoter is dependent on Myc Box II (MBII), basic region (BR), helix-loop-helix (HLH) region and the leucine zipper (LZ) domains. In addition, we demonstrate that Myc repression of the C/EBP $\delta$ promoter is dependent on Miz1 and Max; two Myc interacting proteins that are constitutively associated with the $\mathrm{C} / \mathrm{EBP} \delta$ proximal promoter. Miz1 is required for Myc repression of C/EBP $\delta$ promoter activity but Miz1 does not activate the C/EBP $\delta$ promoter in nontransformed mammary epithelial cells. These results indicate that Miz1 functions exclusively in Myc mediated repression of C/EBP $\delta$ in nontransformed mammary epithelial cells. In addition, endogenous C/EBP $\delta$ expression is increased in cells treated with Miz1 and Max siRNAs, supporting a role for both Max and Miz1 in Myc repression of C/EBPS expression. Finally, RuvBl1 (Pontin, TIP49) and RuvBl2 (Reptin, TIP48), two AAA+ family DNA helicases that interact with Myc Box II, repress C/EBP $\delta$ promoter activity [45]. These results provide new insights into Myc protein-protein interactions and the functional roles of Miz1, Max, RuvBl1 and RuvBl2 in Myc repression of C/EBP $\delta$ expression.

\section{Results}

Myc represses C/EBP $\delta$ promoter activity in nontransformed HC11 mammary epithelial cells

To investigate the role of Myc as a repressor of C/EBP $\delta$ gene transcription we first determined Myc and C/EBPS protein levels in actively cycling (growing (GR)) and growth arrested (GA), nontransformed HC11 mammary epithelial cells. The results confirmed that Myc protein levels are elevated in growing $\mathrm{HC} 11$ cells and reduced in growth arrested $\mathrm{HC} 11$ cells (Figure 1AB). Conversely, C/ $\mathrm{EBP} \delta$ protein levels are virtually undetectable in growing HC11 cells and C/EBP $\delta$ protein levels are induced in growth arrested $\mathrm{HC} 11$ cells (Figure 1AB). Cyclin D1, a labile G1/S marker, is elevated in growing HC11 cells and reduced in growth arrested cells, paralleling Myc protein levels and confirming $\mathrm{HC} 11$ growth (cell cycle) status in 


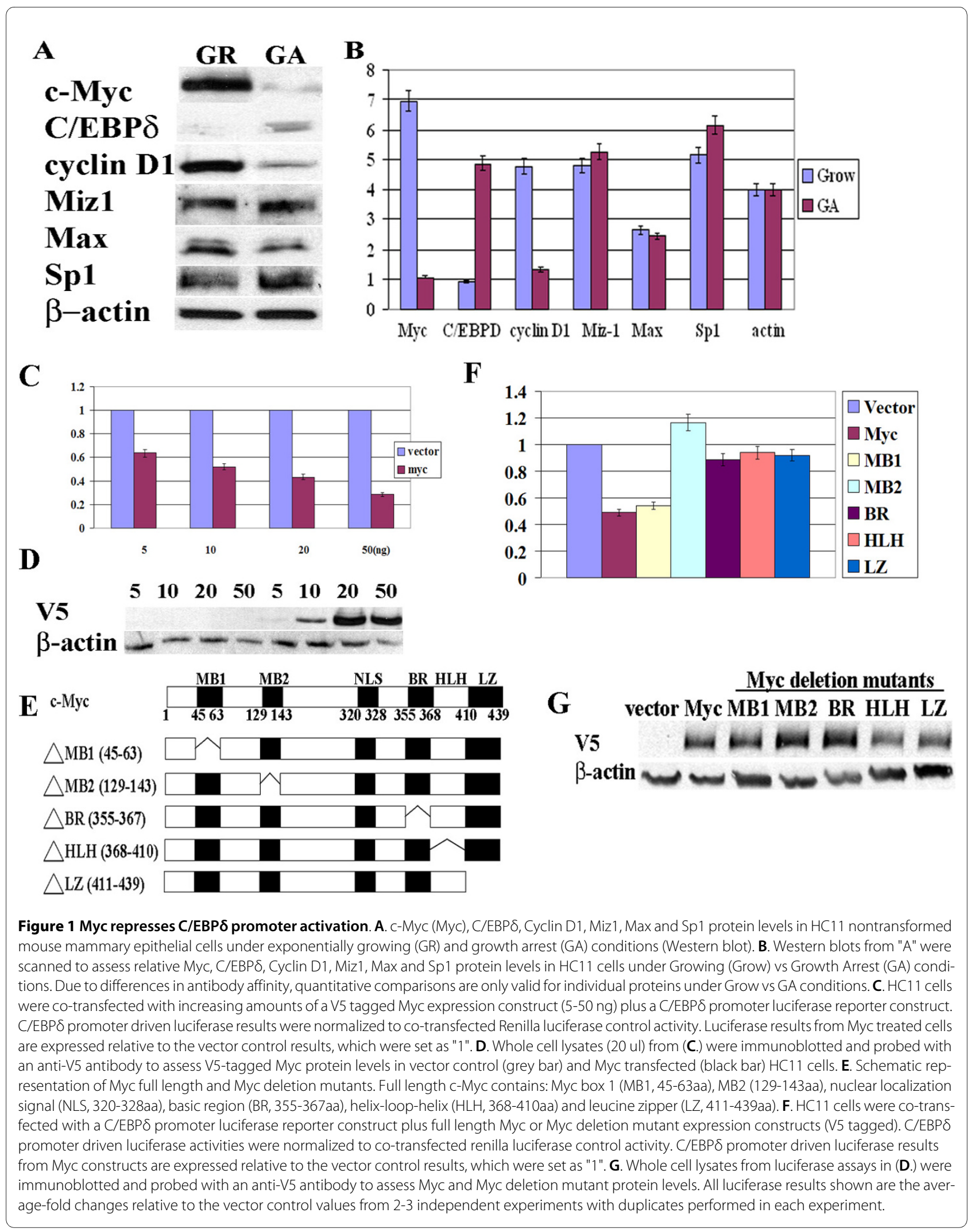


these experiments [46,47]. Myc binding partners Miz1 and Max are also present at relatively constitutive levels in growing and growth arrested $\mathrm{HC} 11$ cells (Figure 1AB). Induction of $\mathrm{C} / \mathrm{EBP} \delta$ gene transcription requires the transcriptional activator Sp1 $[7,48,49]$. Sp1 protein levels, however, are unaffected by cell cycle status (Figure 1AB). These results demonstrate that Myc and C/EBP $\delta$ protein levels are directly influenced by growth status and that Myc and C/EBP protein levels are inversely correlated in nontransformed HC11 mammary epithelial cells.

To investigate Myc repression of C/EBP $\delta$ promoter activity, HC11 cells were transfected with increasing amounts of Myc (5 50 ng) plus a C/EBP $\delta$ promoter luciferase construct (Figure 1C). Myc repressed C/EBPS promoter activity in a dose-dependent manner, even at dose levels as low as $5 \mathrm{ng}$ (Figure 1C). Expression of Myc constructs was confirmed by Western blot analysis of cell lysates (Figure 1D). To map the domains of Myc essential for the repression of C/EBP $\delta$ promoter activity, Myc deletion mutants corresponding to Myc box 1 ( $\triangle \mathrm{MB1}, 45-63)$, Myc box 2 ( $\triangle \mathrm{MB} 2,129-143)$, basic region $(\triangle \mathrm{BR}, 355-$ 367), helix-loop-helix ( $\triangle \mathrm{HLH}, 368-410)$ and leucine zipper $(\Delta \mathrm{LZ}, 411-439)$ were constructed (Figure $1 \mathrm{E})$. The full length Myc construct and the Myc MB1 deletion mutant both repressed C/EBP $\delta$ promoter activity to $\sim 50 \%$ of the empty vector control. These results indicate that the Myc MB1 deletion mutant is nearly as effective as the full length Myc construct in repressing C/EBP $\delta$ promoter activity and therefore, the Myc MB1 region is not required for Myc repression of $\mathrm{C} / \mathrm{EBP} \delta$ promoter activity (Figure 1F). In contrast, the Myc MB2, BR, HLH and LZ deletion mutants all resulted in C/EBP $\delta$ promoter activity that was similar to the empty vector control (Figure 1F). These results demonstrate that the MB2, BR, and the $\mathrm{HLH} / \mathrm{LZ}$ regions are required for Myc repression of C/ EBP $\delta$ promoter activity. Western blots demonstrated that the protein levels of the individual transfected Myc constructs were approximately equal; indicating that differences in C/EBP $\delta$ promoter activity were not due to variations in the expression of the transfected Myc constructs (Figure 1G).

\section{Miz1 (Myc-interacting zinc-finger protein 1) is constitutively associated with the C/EBP $\delta$ promoter; Myc interacts with Miz1 in the repression of C/EBP $\delta$ promoter activity}

Myc represses gene promoters by interacting with DNA bound transcription factors including Sp1 and Miz1 [44]. To identify the Myc interacting protein implicated in Myc repression of the C/EBP $\delta$ promoter we transfected $\mathrm{HC} 11$ cells with V5-tagged Myc expression constructs and performed co-immunoprecipitations to assess Myc/Miz1 and $\mathrm{Myc} / \mathrm{Sp} 1$ interactions in $\mathrm{HC} 11$ cell lysates. The results demonstrated that Myc interacts with Miz1, but not Sp1, supporting a role for Myc/Miz1 repression of the C/EBPS promoter (Figure 2A). We next used ChIP assays to investigate the association between Myc and Miz1 and the C/EBPS proximal promoter (P200) in Growing ("Gr", C/EBP $\delta$ non-expressing) and growth arrested ("GA", C/ EBP $\delta$ expressing) HC11 cells. The ChIP results demonstrated that both Myc and Miz1 associate with the $\mathrm{C} /$ EBP $\delta$ proximal (P200) promoter in $\mathrm{HC} 11$ cells under Growing ("Gr", C/EBP $\delta$ non-expressing) conditions (Figure 2B). Miz1 remains associated with the $\mathrm{C} / \mathrm{EBP} \delta$ proximal (P200) promoter under growth arrest ("GA", C/EBPS expressing) but Myc is not associated with the C/EBP $\delta$ proximal (P200) promoter in growth arrested (GA) HC11 cells (Figure 2B). Regardless of the growth conditions, neither Miz1 nor Myc is associated with the distal C/ EBP $\delta$ promoter region located $1.8 \mathrm{~kb}$ upstream of the $\mathrm{C} /$ EBP $\delta$ transcription start site (P1.8K) (Figure 2B). These results are consistent with the presence a Myc/Miz1 complex in association with the C/EBP $\delta$ proximal promoter during active cell proliferation when C/EBP $\delta$ gene transcription is repressed and the absence of Myc in association with the C/EBP $\delta$ proximal promoter during growth arrest when C/EBP $\delta$ gene transcription is highly induced [6]. The negative ChIP results from the distal C/EBP $\delta$ promoter region $1.8 \mathrm{~kb}$ upstream of the C/EBP $\delta$ transcription start site (P1.8K) indicate that the Myc repressive complex is localized to C/EBP $\delta$ proximal (P200) region.

To determine if Myc/Miz1 interaction is required for Myc repression of $\mathrm{C} / \mathrm{EBP} \delta$ promoter activation we obtained a mutant Myc construct that is deficient in Miz1 binding (MycV394D, Val ${ }^{394} \mathrm{~T}$ Asp, generous gift from Dr. M. Eilers). To validate the MycV394D Miz1 binding defect co-immunoprecipitation assays were performed on HC11 cells transfected with V5 tagged Myc wild type (wt) or the MycV394D (Miz1 binding deficient) constructs. The results demonstrated that the Myc wt construct (myc) binds to Miz1, but the Myc V394D construct ("394") does not (Figure 2C). To assess the functional significance of Myc/Miz1 binding on Myc repression of $\mathrm{C} /$ EBP $\delta$ promoter activity $\mathrm{HC} 11$ cells were transfected with Myc wt or the MycV394D Miz1 binding deficient mutant plus a C/EBP $\delta$ proximal (P200) promoter-luciferase construct. The results demonstrated that the Miz1 binding deficient MycV394D mutant construct was relatively ineffective in repressing C/EBP $\delta$ promoter activity compared to the Myc wt construct (Figure 2D). Western blots documented the expression of transfected Myc constructs (Figure 2E). These results demonstrate that optimal Myc repression of C/EBP $\delta$ promoter activity requires Miz1.

\section{Miz1 does not activate the C/EBP $\delta$ promoter in} nontransformed HC11 mammary epithelial cells

Previous reports have demonstrated that Miz1 functions as a transcriptional activator and that Myc represses Miz1 target gene activation [39]. Miz1 is associated with 

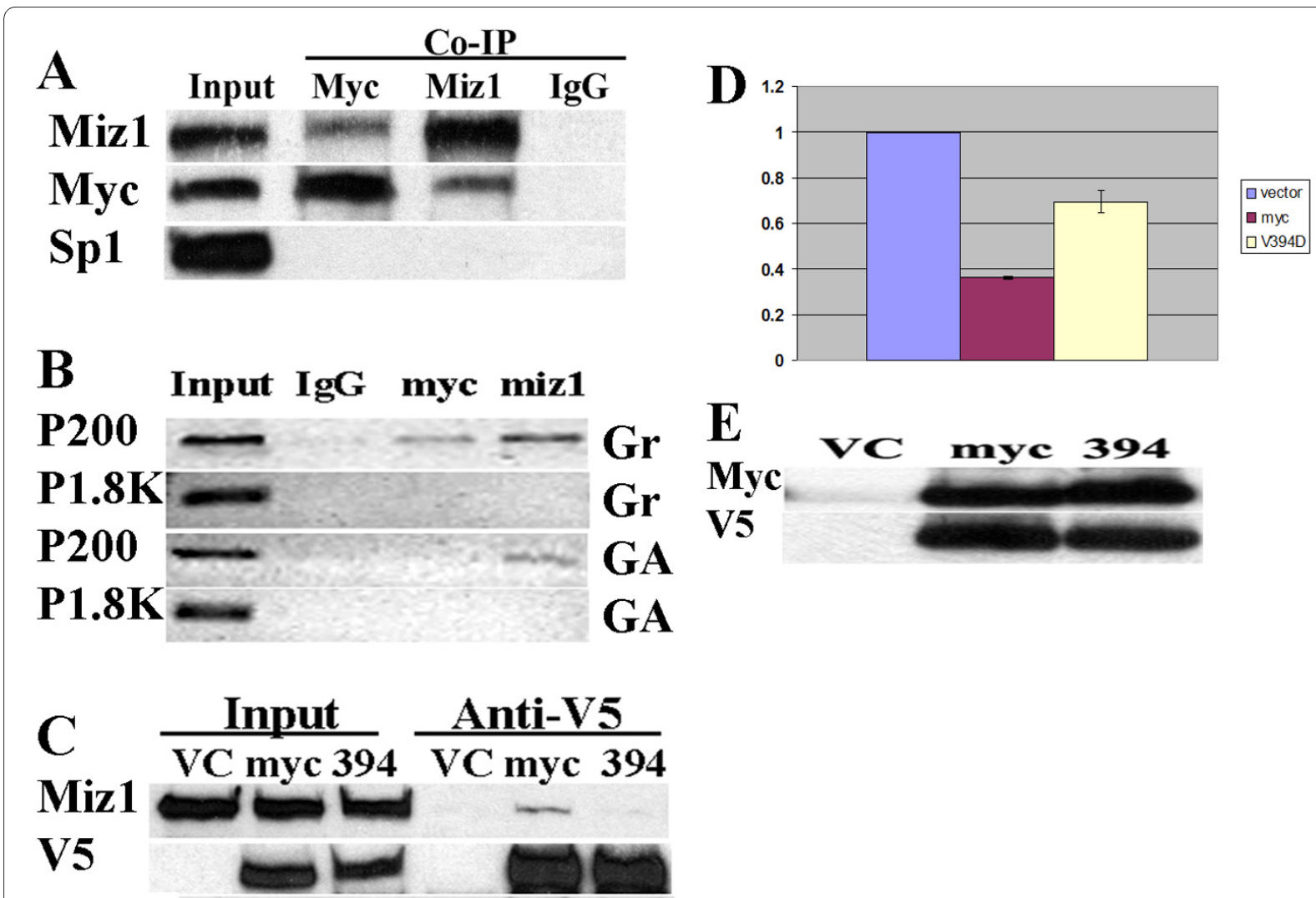

Figure 2 Myc interacts with Miz1; Miz1 plays a key role in Myc repression of C/EBPס promoter activity. A. HC11 cell lysates were immunoprecipitated with anti-Myc and anti-Miz1 antibodies and the immunoprecipitates analyzed by Western blot using anti-Myc, Miz1 and Sp1 antibodies. "Input": western blot analysis of HC11 whole cell lysates (positive control). "IgG": nonspecific rabbit IgG immunoprecipitates (negative control). B. HC11 cell chromatin was immunoprecipitated using antibodies against Myc or Miz1. Immunoprecipitated DNA was amplified using primers flanking the C/ EBPS proximal (P200) promoter region and the distal (P1.8K) C/EBPS upstream promoter regions. "Input" results are derived from direct PCR amplification of P200 and P1.8K C/EBP $\delta$ promoter regions from HC11 genomic DNA (Positive control). IgG: nonspecific rabbit lgG immunoprecipitated (negative control). C. HC11 cells were transfected with vector control, Myc wt or Myc V394D expression constructs (V5-tagged). Co-immunoprecipitation was performed using an anti-V5 antibody. Immunoprecipitates were analyzed by Western blot using anti-Miz1 and anti-V5 antibodies. D. HC11 cells were co-transfected with a C/EBPS promoter luciferase reporter construct, vector control, Myc wild type (wt) or Myc V394D. C/EBPS promoter driven luciferase activities were normalized to renilla luciferase activity. Results for the Myc transfected cells are expressed relative to the vector control results which were set as "1". E. Whole cell lysates (20 ul) from lucifease assays in (D.) were analyzed by Western blot to assess Myc wt and Myc V394D expression. Luciferase results shown are the average-fold changes relative to the vector control values from 2 independent experiments with duplicates performed in each experiment.

the C/EBPS proximal promoter during growth arrest (Figure $2 \mathrm{~B}$ above) when $\mathrm{C} / \mathrm{EBP} \delta$ is actively transcribed [6], suggesting that Miz1 may function as a transcriptional activator of C/EBP $\delta$ transcription. To investigate Miz1 transcriptional activation of the C/EBPS promoter HC11 cells were co-transfected with a Miz1 expression construct plus a C/EBP $\delta$ proximal promoter-luciferase (P200) construct. The results demonstrate that Miz1 expression does not increase $\mathrm{C} / \mathrm{EBP} \delta$ promoter activity in proliferating (growing, Gr), or in growth arrested (GA) HC11 cells (Figure 3A). As expected, C/EBP $\delta$ promoter activity is higher in growth-arrested vs growing $\mathrm{HC} 11$ cells $[6,7]$. Western blot analysis of HC11 cell lysates demonstrate the increased levels of Miz1 in HC11 cells trans- fected with the Miz1 expression construct and confirm the presence of Myc protein levels in growing $(\mathrm{Gr})$ cells and the absence of Myc in growth arrested (GA) cells (Figure 3B).

Although Miz1 over expression had no effect on C/ EBP $\delta$ promoter activity, reducing Miz1 levels by Miz1 siRNA treatment had a profound effect on C/EBPS promoter activity in growing $(\mathrm{Gr}) \mathrm{HC} 11$ cells. C/EBP $\delta$ promoter activity was induced $\sim 2.5$ fold in Miz1 siRNA treated; growing (Gr) HC11 cells (Figure $3 \mathrm{C}$ ). Reducing Miz1 levels, however, had no effect on C/EBP $\delta$ promoter activity in growth arrested (GA) HC11 cells (Figure 3C). These results indicate that reducing Miz1 levels increases C/EBPS promoter activity in proliferating cells, presum- 

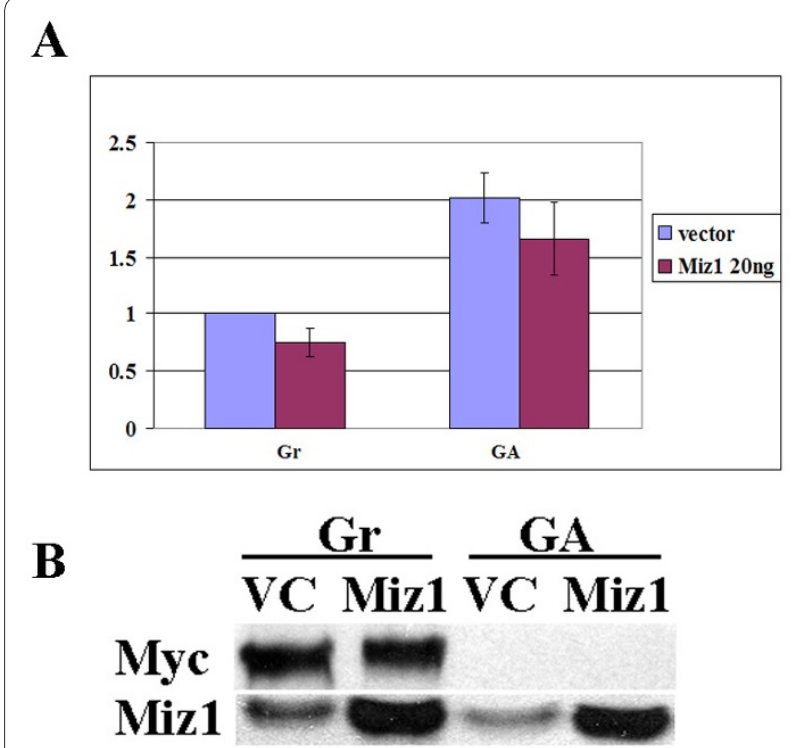

$\mathbf{E}$

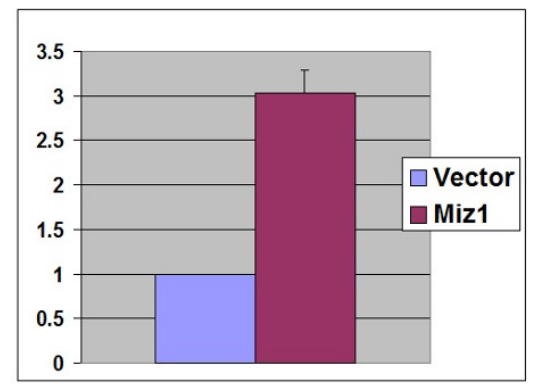

C

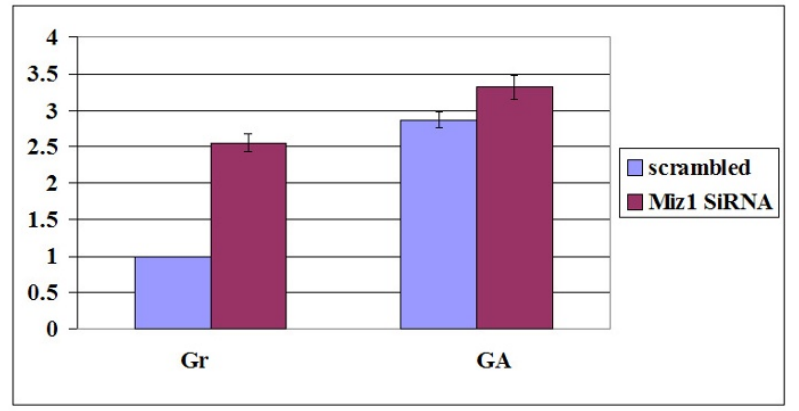

$\mathbf{D}$

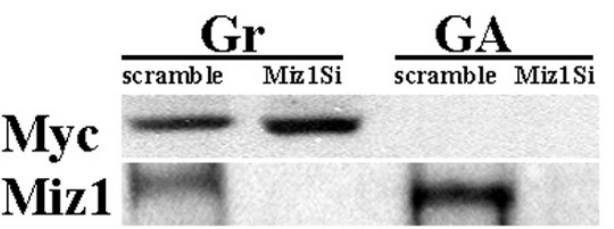

Figure 3 Miz1 functions in Myc repression of C/EBPס promoter activity. A. HC11 cells were co-transfected with Miz1 or a vector control plus a C/ EBP $\delta$ promoter luciferase construct and Renilla control. Luciferase activity was assessed under Growing (Gr) (Myc expressed, C/EBPS repressed) or growth arrest (GA) (Myc not expressed, C/EBPS expressing) conditions. Luciferase results were normalized to the Renilla control. C/EBP $\delta$ promoter driven luciferase results from Miz1 transfected cells are expressed relative to the vector control, "Gr" results which were set as "1". B. Lysates from luciferase assays (A.) were analyzed by Western blot to assess Myc and Miz1 protein levels. $\beta$-actin levels were assessed as a loading control. C. HC11 cells were transfected with Miz1 siRNA treatment and C/EBPS promoter driven luciferase assays performed as described. Luciferase results were normalized to the Renilla control. C/EBP $\delta$ promoter driven luciferase results from Miz1 siRNA treated cells are expressed relative to the vector control, "Gr" results which were set as "1". D. Lysates from luciferase assays (C.) were analyzed by Western blot to assess Myc and Miz1 protein levels. $\beta$-actin levels were assessed as a loading control. Luciferase results for the Miz1 expression and Miz1 siRNA treatment groups shown are the average-fold changes relative to the "scrambled" siRNA values from 2 independent experiments with duplicates performed in each experiment. E. HEPG2 cells were cotransfected with Miz1 or a vector control plus a low density lipoprotein receptor (LDLR) promoter luciferase construct and Renilla control. Luciferase results were normalized to the Renilla control. LDLR promoter driven luciferase results from Miz1 transfected cells are expressed relative to the vector control results which were set as "1".

ably by reducing Miz1/Myc repression (Figure 2D). Interestingly, C/EBP $\delta$ promoter activity is not altered by reducing Miz1 levels in growth arrested HC11 cells (Figure 3C). These results indicate that Miz1 does not increase C/EBP $\delta$ promoter activity during growth arrest. Western blot analysis of $\mathrm{HC} 11$ cell lysates confirmed that siRNA treatment was highly effective in reducing Miz1 protein levels (Figure 3D). To verify that Miz1 can function as a transcriptional activator in the proper cell context HEPG2 cells were transfected with a Miz1 expression construct plus a low-density lipoprotein receptor (LDLR) promoter-luciferase construct essentially as described by Tjian and co-workers [50]. The results demonstrated that Miz1 functions as a transcriptional activator of the LDLR promoter in HEPG2 cells (Figure 3E). These results demonstrate that Miz1 functions exclusively in Myc repression of C/EBP $\delta$ promoter activity under growing (proliferating) conditions but Miz1 does not activate C/ EBP $\delta$ promoter activity in growth arrested HC11 nontransformed mammary epithelial cells. 


\section{Miz1 binds to the -100 to -70 region of the C/EBP $\delta$ proximal promoter}

Myc functions as a transcriptional repressor by binding to DNA-bound Miz1 [28]. Miz1 binds to highly divergent proximal promoter transcription initiator (Inr) elements [28]. To investigate Miz1 binding to the C/EBP $\delta$ promoter we performed electromobility shift assays (EMSAs) using recombinant mouse Miz1 and fluorescent labeled C/EBP $\delta$ proximal promoter fragments. The initial results confirmed Miz1 binding to the -140 to $+30 \mathrm{C} /$ EBPS proximal promoter (Figure 4A). To localize the region of Miz1 binding we performed EMSAs using C/ EBP $\delta$ promoter fragments deleted from the $3^{\prime}$ and $5^{\prime}$ ends. Miz1 binding was retained in all C/EBPS proximal promoter fragments deleted from the 3 ' end, indicating that Miz1 binding was localized within -140 to -70 region of the C/EBP $\delta$ proximal promoter (Figure 4B). Deletions from the $5^{\prime}$ of the $C / E B P \delta$ proximal promoter indicated that the Miz1 binding was localized within the -110 to -80 region of the C/EBP $\delta$ proximal promoter (Figure $4 \mathrm{C}$, lanes $\mathrm{f}, \mathrm{g}$ ). To further investigate Miz1 binding EMSAs were performed with recombinant Miz1 protein and short ( 30 bp) C/EBP $\delta$ proximal promoter fragments spanning the following regions of the C/EBP $\delta$ proximal promoter: -127 to $-100 \mathrm{bp}$ (Probe "h"), -100 to $-70 \mathrm{bp}$ (Probe "i") and +1 to +30 (Probe "j", a negative EMSA control). The results demonstrated weak Miz1 binding to the -127 to -100 region ("h"), strong Miz1 binding to the 100 to -70 region ("i"), and no detectable Miz1 binding to the +1 to +30 region ("j") (Figure 5A). We next performed individual competition assays with the same 3 C/EBP $\delta$ promoter fragments and the C/EBP $\delta-140$ to +30 proximal promoter fragment. The results demonstrated that the -100 to -70 ("i") C/EBP $\delta$ promoter fragment was the most effective in reducing Miz1 binding to the C/EBP $\delta$ 140 to +30 proximal promoter fragment (Figure $5 \mathrm{~B}$ ). The -127 to $-100 \mathrm{C} / \mathrm{EBP} \delta$ promoter exhibited a limited capacity to compete with the $\mathrm{C} / \mathrm{EBP} \delta-140$ to +30 proximal promoter fragment for Miz1 binding, consistent with the weak binding to this region demonstrated in Figure 5A. Although Inr sequences are highly degenerate, a candidate Inr sequence is located at -85 to -93 (5'-CCCCAGTCCCT-3') of the C/EBPS proximal promoter, within the -100 to -70 region [6].

Max is constitutively associated with the C/EBP $\delta$ promoter and functions in the repression of C/EBP $\delta$ promoter activity Myc Associated protein $\mathrm{X}$ (Max) is a ubiquitously expressed, long lived ( $t / 2>24$ hours) helix loop helix/ leucine zipper (HLH/bZIP) protein that heterodimerizes with Myc and is required for Myc transcriptional activation and repression [51-53]. Using ChIP assays, we assessed the association between Max and the C/EBP $\delta$ promoter under growing and under growth arrest condi- tions. The results indicated that Max is associated with the C/EBP $\delta$ promoter under both growing (GR, C/EBP $\delta$ expression repressed) and growth arrest (GA, C/EBP $\delta$ expression highly induced) conditions (Figure 6A). To determine if Max is required for Myc repression of $\mathrm{C} /$ EBP $\delta$ promoter activity $\mathrm{HC} 11$ cells were treated with Max siRNA and C/EBP $\delta$ promoter driven luciferase activity assessed. The results indicated that Max siRNA treatment reduces Myc repression of $\mathrm{C} / \mathrm{EBP} \delta$ promoter activity and this reduction in Myc repression is comparable to Miz1 siRNA treatment (Figure 6B). These results demonstrate that Max is constitutively associated with the C/EBP $\delta$ promoter and plays a key role in Myc repression of C/EBP $\delta$ promoter activity.

IL-6 and Oncostatin M (OSM) induce STAT3 activation (phosphorylation) and phosphorylated STAT3 (pSTAT3) activates C/EBP $\delta$ transcription in growth arrested cells $[7,8,54]$. OSM activates pSTAT3, but pSTAT3 does not fully activate C/EBP $\delta$ expression in proliferating (growing) cells due to Myc repression [43]. Myc repression of OSM induced endogenous C/EBP $\delta$ expression is attenuated by Myc siRNA treatment [43]. To investigate the role of Max and Miz1 in Myc repression of endogenous C/EBP $\delta$ expression HC11 cells were transfected with Max and Miz1-specific siRNAs. Endogenous $C / E B P \delta$ expression was assessed by western blot of whole cell lysates from actively proliferating (growing) vector control, Max and Miz1 siRNA treated HC11 cells treated with OSM. The results demonstrated that Max and Miz1 siRNA treatments reduced endogenous Max and Miz1 protein levels and the individual reductions in Max and Miz1 protein levels were associated with increased OSM-induced C/EBP $\delta$ protein levels compared to scrambled or "Junk" siRNA treated HC11 cells (Figure 6C). These results indicate that Max and Miz1 function in repression of endogenous $\mathrm{C} / \mathrm{EBP} \delta$ gene expression.

\section{RuvBI1 (Pontin, TIP49) and RuvBI2 (Reptin, TIP48) repress C/ EBPS promoter activity}

RuvBl1 (Pontin, TIP49) and RuvBl2 (Reptin, TIP48) are members of the highly conserved AAA+ (ATPases associated with diverse cellular activities) superfamily with functions in chromatin remodeling and transcriptional regulation [45]. We hypothesized that RuvBl1 (Pontin, TIP49) and RuvBl2 (Reptin, TIP48) may contribute to Myc repression of C/EBPS promoter activity as both proteins interact with Myc Box II and enhance Myc transcriptional repression and Myc mediated transformation $[25,34,53,55]$. In addition, RuvBl1 (Pontin) and RuvBl2 (Reptin) are overexpressed in a variety of human cancers [45]. To investigate the role of RuvBl1 and RuvBl2 in Myc repression of C/EBP $\delta$ promoter activation RuvBl1 and RuvBl2 expression constructs were transfected into proliferating $\mathrm{HC} 11$ cells and $\mathrm{C} / \mathrm{EBP} \delta$ promoter activity 
A

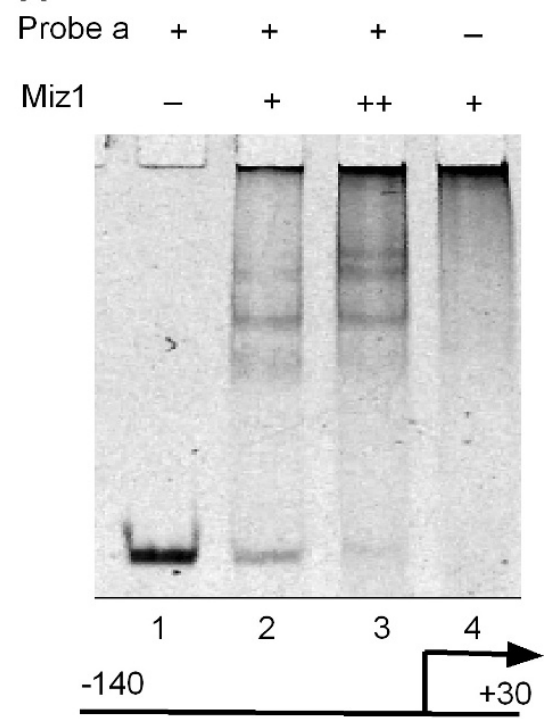

Mouse C/EBPó Promoter
B

Probe $\frac{\mathrm{a}}{\mathrm{c}} \stackrel{\mathrm{d}}{\mathrm{B}}$

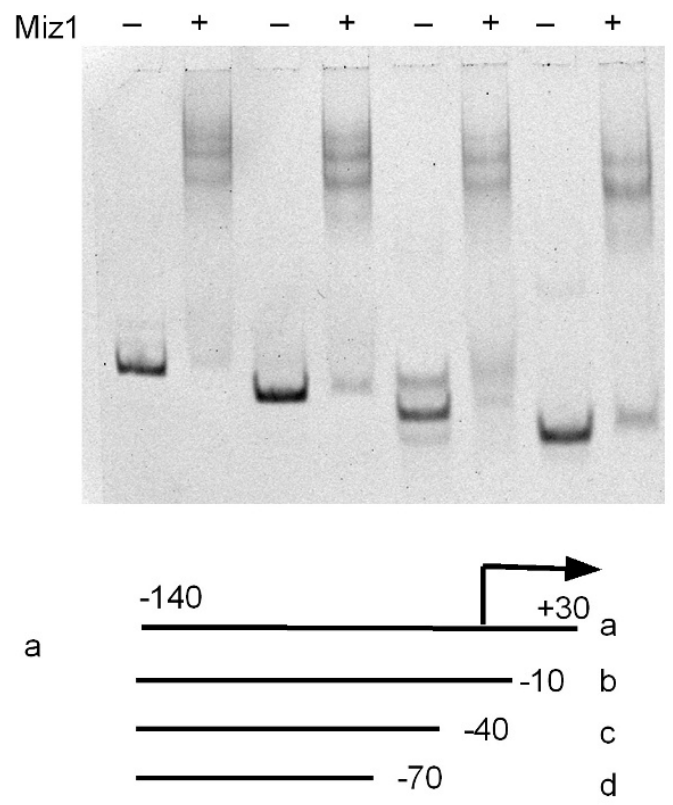

C

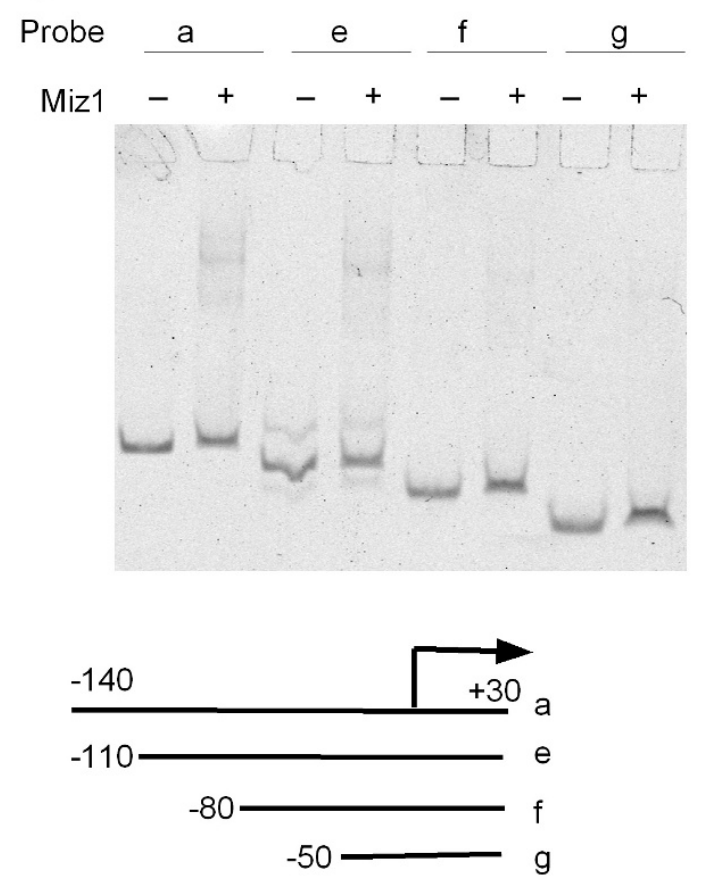

Figure 4 Miz1 binds to the C/EBP $\delta$ proximal promoter. A. Miz1 binds to the C/EBP $\delta$ promoter (170 bp, - 140 to +30$)$. Lanes: (1) C/EBP $\delta 170$ bp pro-

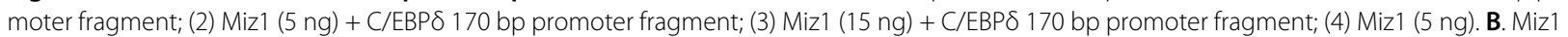
binds to the C/EBPS promoter 5 ' region. Lanes: a. C/EBP $\delta$ promoter fragment (-140 to +30), - or + Miz1 (5 ng); b. C/EBP $\delta$ promoter fragment (-140 to -10), - or + Miz1; C. C/EBP $\delta$ promoter fragment (-140 to -40), - or + Miz1; d. C/EBP $\delta$ promoter fragment (-140 to -70), - or + Miz1. C. Miz1 does not bind to C/EBP $\delta$ promoter fragments with the -110 to -80 region deleted. Lanes: a. C/EBP $\delta$ promoter fragment $(-140$ to +30$)$, - or + Miz1 (5 ng); e. C/EBP $\delta$ promoter fragment $(-110$ to +30$)$, - or + Miz1; f. C/EBP $\delta$ promoter fragment (-80 to +30), - or + Miz1; g. C/EBP $\delta$ promoter fragment $(-50$ to +30$)$, - or + Miz1. Results are representative of 3 EMSA experiments. 


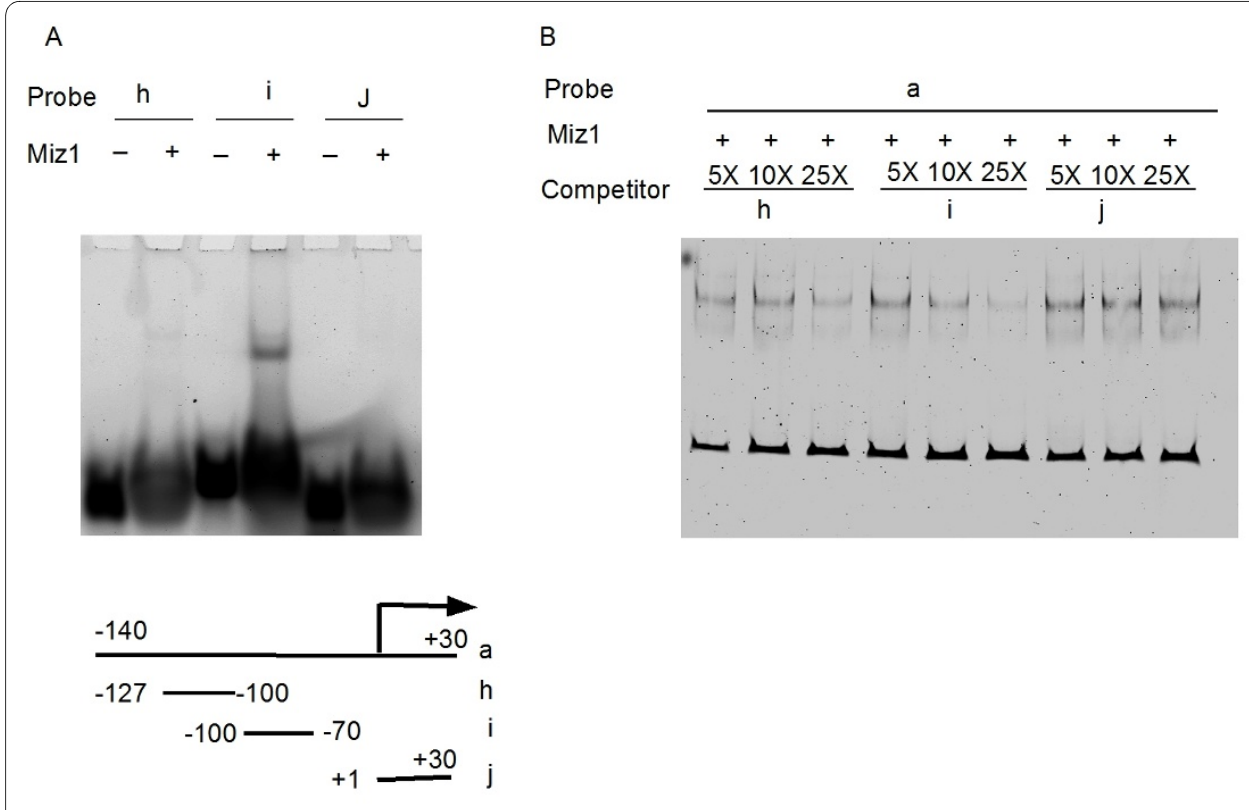

Mouse C/EBPó Promoter

Figure 5 Miz1 binding is localized to the $-\mathbf{1 0 0}$ to $-\mathbf{7 0}$ region of the C/EBPס proximal promoter (Probe "i"). A. EMSAs were performed without Miz1 (-) or with Miz1 (+) (5 ng) plus the following C/EBPS proximal promoter fragments: -127 to -100 bp (Probe "h"); - 100 to -70 (Probe "i"); or +1 to +30 (Probe "j") - or + Miz1 (5 ng). B. Competition EMSAs: C/EBPS -100 to -70 proximal promoter fragment (Probe "i") effectively competes for Miz1 binding with the "full length" -140 to +30 C/EBP $\delta$ proximal promoter fragment. Miz1 was incubated with the "full length" -140 to $+30 \mathrm{C} / \mathrm{EBP} \delta$ proximal promoter fragment (Probe "a") plus $5 \times, 10 \times$ and $25 \times$ molar excess of C/EBPS proximal promoter fragments: -127 to -100 bp (Probe "h"); -100 to -70 (Probe "i"); or +1 to +30 (Probe "j"). Results are representative of 2 EMSA experiments.

assessed by luciferase assay. The results demonstrated that both RuvBl1 and RuvBl2 repress C/EBP $\delta$ promoter activity in a dose-dependent manner (Figure 7A). In addition to assessing the repressive effects of RuvBl1 and RuvBl2 individually, the repressive effect of co-transfecting RuvBl1 and RuvBl2 on C/EBP $\delta$ promoter activity was also investigated. The results demonstrated that coexpression of RuvBl1 and RuvBl2 was more effective in repressing $\mathrm{C} / \mathrm{EBP} \delta$ promoter activity than expression of either RuvBl1 and RuvBl2 alone (Figure 7A). Western blot analysis documented the expression of the transfected constructs and the positive correlation between increased RuvBl1 and RuvBl2 expression levels and increased repression of C/EBP $\delta$ promoter activity (Figure 7B).

\section{Discussion}

The findings from this study demonstrate that Myc represses C/EBP $\delta$ expression by associating with the $\mathrm{C} /$ EBP $\delta$ proximal promoter as transient component of a multi-protein repressive complex. Transcriptional repression is a major mechanism of Myc oncogenesis and Myc repressed genes include critical regulators of cell cycle progression, growth arrest and differentiation such as $\mathrm{p} 21^{C I P 1}$, $\mathrm{p} 27^{K I P 1}, \mathrm{p} 15^{I N K 4}$, $\mathrm{p} 18^{I N K 4 c}$, $\mathrm{p} 57^{K I P 2}$, gas1, and C/ EBPa [44]. Myc repression of C/EBP $\delta$ transcription is
Miz1 dependent, indicating that Myc repression of $\mathrm{C} /$ EBPS transcription parallels Myc repression of p15 ${ }^{I N K}$, p21 ${ }^{C I P 1}$, p27 ${ }^{K I P 1}$, Mad4 and C/EBPa [25]. However, Miz1 does not function as a transcriptional activator of the $\mathrm{C} /$ EBP $\delta$ promoter in nontransformed mammary epithelial cells, differentiating Miz1 function in the regulation of $\mathrm{C} /$ EBPS from $\mathrm{p} 15^{I N K}$, $\mathrm{p} 21^{C I P 1}$ and Mad4 [44]. Although Miz1 does not activate the C/EBP $\delta$ promoter, ChIP assays demonstrated that Miz1 is constitutively associated with the C/EBP $\delta$ promoter. EMSA analysis localized the Miz1 binding site to the -100 to -70 region of the C/EBP $\delta$ proximal promoter. This a region contains a candidate Inr $(-85$ to -93) immediately downstream of STAT3/Sp1 consensus sites $(-120$ to -104$)$ that are associated with C/EBP $\delta$ transcriptional activation $[7,54]$. We and others have reported that pSTAT3 is a potent transcriptional activator of $\mathrm{C} / \mathrm{EBP} \delta$ gene expression $[7,8]$. The presence of the Miz1 binding site downstream of the C/EBP $\delta$ consensus transcriptional activation sites provides a rationale for how Myc represses C/EBP $\delta$ expression in actively cycling cells that exhibit increased pSTAT3 in response to IL-6 family cytokines [43]. These findings suggest that Myc repression of $\mathrm{C} / \mathrm{EBP} \delta$ expression could contribute to the cascade of Myc mediated events that result in aberrant cell proliferation and enhanced transformation. 


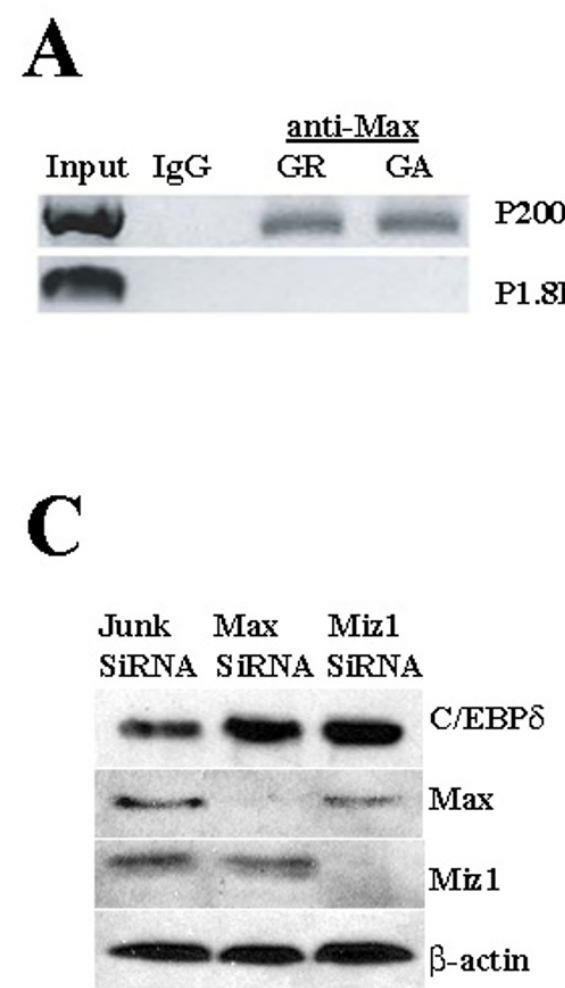

B

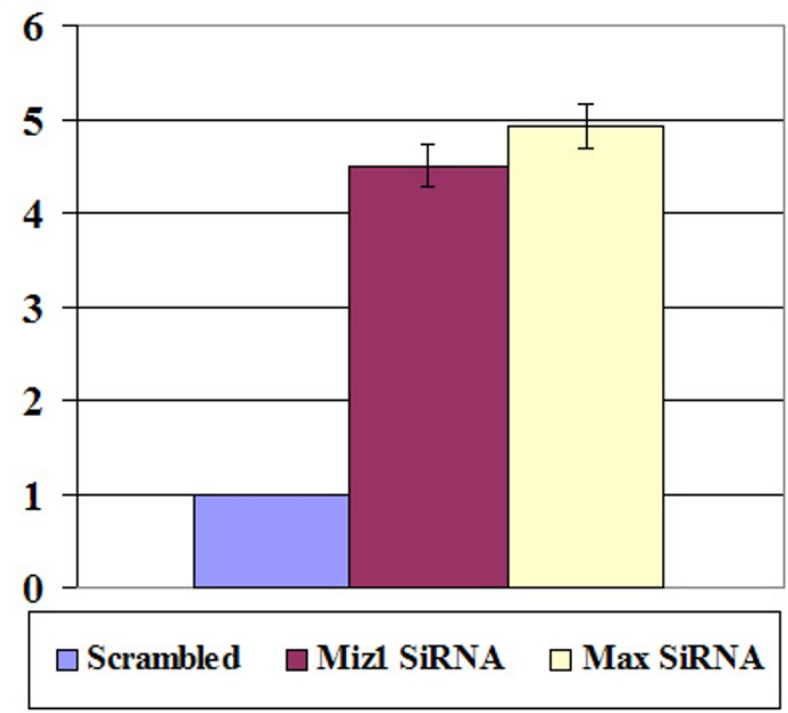

Figure 6 Max is required for Myc repression of the C/EBPS promoter activity. A. ChIP assays were performed on chromatin isolated from growing (GR) and Growth arrest (GA) HC11 cells using anti-Max antibodies. Immunoprecipitated DNA was amplified using primers flanking the C/EBPS proximal promoter region (P200) and the C/EBPS upstream promoter region (P1.8K). "Input" results are derived from PCR amplification of HC11 genomic DNA. Normal rabbit IgG was used as negative control. B. Growing HC11 cells were nucleofected with the "scrambled" siRNA control, Miz1 siRNA and Max siRNA. C/EBPS promoter-luciferase results were normalized to the Renilla control. The luciferase results for the "scrambled" siRNA control were set as "1". Luciferase results for the Miz1 and Max siRNA treatment groups shown are the average-fold changes relative to the "scrambled" siRNA control values from 3 independent experiments with duplicates performed in each experiment $(n=6)$. C. HC11 cells were nucleofected with a scrambled siRNA, Max or Miz1 siRNA constructs using the Amaxa nucleofector protocol. Nucleofected HC11 cells were then cultured in complete growth media (proliferating, growing conditions) in the presence of OSM (GROW + OSM). Whole cell lysates were isolated and analyzed by Western blot using antiC/EBPS, Max and Miz1 antibodies (lane 1-3). $\beta$-actin was assessed as the loading control. The results shown are representative of three independent experiments.

Max, a well-established Myc binding partner, also plays a key role in Myc repression of C/EBPS expression. Like Miz1, Max is constitutively associated with the C/EBP $\delta$ promoter even in the absence of Myc, a finding that is consistent with a previous report by Mao, et al, [52]. The recruitment of Miz1 and Max to the C/EBP $\delta$ proximal promoter may be facilitated by the $\mathrm{C} / \mathrm{EBP} \delta$ proximal promoter "open" chromatin conformation [43]. We previously reported that the $\mathrm{C} / \mathrm{EBP} \delta$ proximal promoter is in an open chromatin conformation and "pre-loaded" with transcriptional machinery components associated with transcriptional activation including Sp1, cyclic AMP response element-binding protein (CREB), TATAA Binding protein (TBP) and RNA Pol II [43]. The present results demonstrate that Miz1 and Max, two proteins that function in $\mathrm{C} / \mathrm{EBP} \delta$ transcriptional repression, are also constitutively associated with the C/EBP $\delta$ promoter. These results are consistent with a model in which the $\mathrm{C} /$ EBPS proximal promoter exists in a unique state, poised for activation or repression by the constitutive presence of proteins that mediate both transcriptional activation and repression.

Although Myc transcriptional repression is critical for Myc mediated cell transformation, the proteins that interact with Myc and function in gene repression are poorly characterized. RuvBl1 (Pontin, TIP49) and RuvBl2 (Reptin, TIP48) are two AAA+ ATPase helicases that interact with Myc Box II and function in Myc transcriptional repression, and have been shown to increase cell proliferation and transformation [55-57]. Individually, 


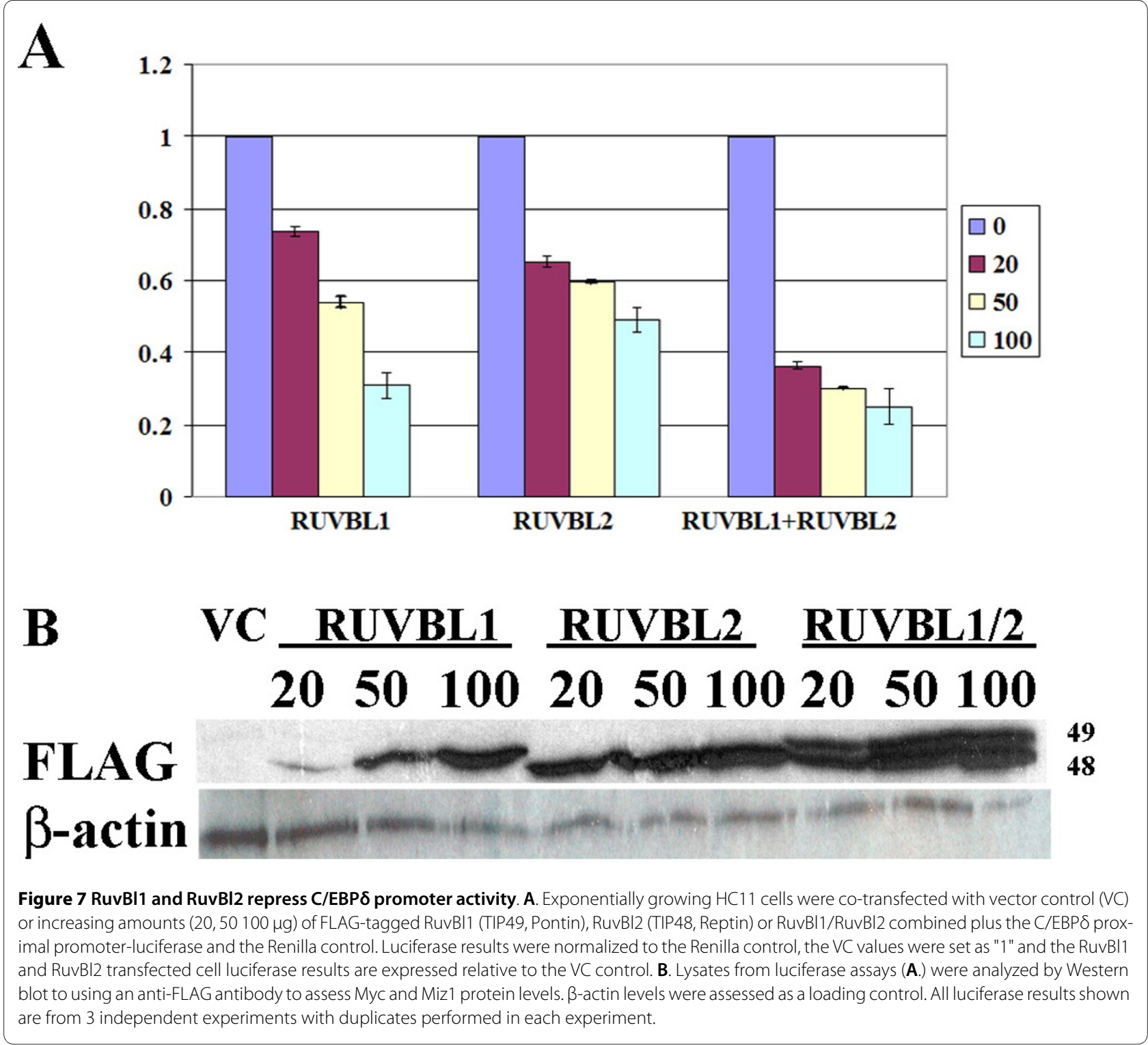

both RuvBl1 and RuvBl2 repressed C/EBP $\delta$ promoter activity, however, co-expression of RuvBl1 and RuvBl2 was most effective in repressing C/EBP $\delta$ promoter activity. This suggests that Myc transcriptional repression of C/EBP $\delta$ may be mediated by a multi-protein complex composed of DNA bound Miz1, Myc/Max and possibly RuvBl1 and RuvBl2. Studies in Xenopus demonstrated that RUVBL1/RUVBL2 (xPontin/xReptin) induce cell proliferation during embryogenesis by enhancing Myc repression of p21 [58]. Our findings suggest that a similar mechanism may mediate Myc repression of C/EBP $\delta$ and possibly other growth suppressor genes (such as p21 Waf1/ $C I P 1)$, in promoting aberrant mammary epithelial cell proliferation and transformation.

Despite the critical role of Myc transcriptional repression in cell transformation, the mechanism by which Myc transcriptional repression leads to cell transformation is poorly understood. Several lines of evidence indicate that Myc can recruit DNA methyltransferases and that Myc transcriptional repression can progress to transcriptional silencing. For example, Myc repression of $\mathrm{p} 21$ Waf $1 / C I P 1$ transcription in human U2OS osteosarcoma cells occurs via formation of a repressive complex including Myc, Miz1 and DNA Methyltransferase3a (Dnmt3a) [59]. In addition, studies in human cervical and hepatocellular carcinoma cells have shown recruitment of DNA methyltransferases and silencing of the human C/EBP $\delta$ (CEBPD) promoter by hypermethylation [21]. Our lab reported that the C/EBP $\delta$ gene is silenced by promoter hypermethylation in the SUM-52PE human breast cancer cell line and that primary breast tumors exhibiting reduced $\mathrm{C} / \mathrm{EBP} \delta$ expression are characterized by site- 
specific promoter methylation $[10,11,54]$. The results from this study demonstrate that Myc repression of $\mathrm{C} /$ EBP $\delta$ transcription is a regulated process that is coordinated with cell cycle status in nontransformed cells. Further studies are needed to determine how this regulated Myc repression function is altered and progresses to gene silencing and cell transformation.

\section{Conclusion}

The results of this study identify protein-protein and DNA-protein interactions that mediate Myc repression of C/EBP $\delta$ gene expression. These results extend current working models of Myc transcriptional repression and suggest future directions to pursue in the characterization of the network of proteins that function in Myc transcriptional repression. The results presented have focused on Myc repression of the mouse C/EBP $\delta$ promoter in HC11 mouse nontransformed mammary epithelial cells; however, human Myc expression constructs also repress the human C/EBP $\delta$ promoter in nontransformed human mammary epithelial cells (MCF-10A) (data not shown). Current experiments are focused on further characterizing Myc interacting proteins, deciphering the sequence of events that mediate Myc repression of C/EBP $\delta$ in nontransformed mouse and human cells, and determining how this sequence progresses to gene silencing and cell transformation. Defining the protein interactions that mediate Myc repression, and the role of Myc in the silencing of tumor suppressor genes, will facilitate the development of pharmacological interventions to inhibit the functions of Myc that promote cell transformation.

\section{Methods}

\section{Cell Culture}

HC11 mouse mammary epithelial cells were grown in complete growth media (CGM) containing RPMI 1640 medium plus $5 \%$ fetal bovine serum (FBS), $10 \mu \mathrm{g} / \mathrm{ml}$ bovine insulin, $10 \mathrm{ng} / \mathrm{ml}$ epidermal growth factor, $100 \mathrm{U} /$ $\mathrm{ml}$ penicillin, $100 \mu \mathrm{g} / \mathrm{ml}$ streptomycin and $500 \mathrm{ng} / \mathrm{ml}$ Fungizone. Growth arrest was induced by $24 \sim 48$ hrs serum and growth factor withdrawal (growth arrest medium, GAM, 0.1\% FBS).

\section{Plasmid Constructs}

Mouse C/EBP $\delta$ proximal promoter sequence flanking 127 bp to transcriptional start site (P-127, containing Sp1, STAT3 and CREB binding sites) was constructed in the pGL2 basic luciferase reporter vector $[7,60]$. Myc and MycV394D mutant constructs in pBabe-puro vector were a generous gift from Dr. Martin Eilers (Institute for Molecular Biology and Tumor Research, University of Marburg, Germany). Myc and MycV394D were then amplified by PCR from pBabe-puro vector using primers specific for Myc. The primer sequences for Myc wild type and MycV394D cloning are as follows: 5'-CGCGGATCCGCGATGCCCCTCAACGTTAGCTTC-3' (forward primer) and 5'-GCTCTAGACGCGCACAAGAGTTCCGTAGCTG-3' (reverse primer). Myc deletion constructs Myc $\Delta 45-63(\mathrm{MB} 1), \quad$ Myc $\Delta 129-143(\mathrm{MB} 2)$, Myc $\Delta 355-367(B R), M y c \Delta 368-410(H L H)$ and Myc $\Delta 411-$ 439(LZ) were constructed by site-specific mutagenesis as previously described [61,62]. Myc-, Myc deletion- and V394D- pcDNA3.1-V5-His expression constructs were verified by sequencing. The Miz1 full length cDNA construct in pCMV6 vector was purchased from Origene.

\section{Transfection Protocol}

HC11 cells were plated in 12-well plates, grown to 50\% confluence in CGM and transfected using the enhanced Lipofectamine transfection protocol (Invitrogen, Carlsbad, CA) as previously described [60]. Co-transfections were performed with $0.3 \mathrm{ug} \mathrm{C} / \mathrm{EBP} \delta$ promoter luciferase reporter construct, $1 \mathrm{ng}$ Renilla luciferase reporter construct (transfection efficiency control), and 5 50 ng of expression constructs or vector controls. For growth arrest experiments, transfected cells were washed $2 \times$ with PBS and cultured in GAM for 24-48 hours. Cells were harvested and assayed for firefly and renilla luciferase activities using the Dual-Luciferase Reporter Assay kit with luciferase detection by Hewlett-Packard Lumicount microplate luminometer as previously described [43]. C/ EBP $\delta$ promoter activities were normalized to renilla luciferase activity. Results shown are the average-fold changes from 3 independent experiments with duplicates. Co-immunoprecipitation experiments were performed as described $[43,61,62]$. HC11 cell lysates used in co-immunoprecipitation assays were prepared by transfecting Myc or V394D Myc mutant expression constructs $(1 \mu \mathrm{g})$ (Lipofectamine) into HC11 cells. HC11 Miz1 and Max siRNA transfections were performed using the Amaxa Nucleofector (Amaxa, Inc., Cologne, Germany). Briefly, HC11 cells were suspended in Amaxa Nucleofector Solution V supplemented with 50 pmol Miz1 or Max Smartpool siRNAs (Dharmacon, Inc., Lafayette, CO) and the nucleofection was performed using cell-type specific protocol (T-20). HC11 cells nucleofected with non-specific scrambled siRNAs were used as controls. Transient siRNA nucleofection protocols were optimized and protocols achieving $>80 \%$ specific gene knockdown as verified by western blot were used in all experiments.

\section{Western blot and co-immunoprecipitation assays}

Western blots were performed on whole cell lysates as previously described [61,62]. Co-immunoprecipitation assays were performed with $\mathrm{HC} 11$ cell lysates isolated by NP-40 lysis, primary antibody immunoprecipitation, Protein A-Agarose bead pull down, elution and analysis by 
SDS PAGE as previously described [61]. Co-immunoprecipitations were performed 2-3 times and representative results presented.

\section{Chromatin immunoprecipitation (ChIP)}

ChIP experiments were performed using the Chromatin Immunoprecipitation (ChIP) Assay Kit (Sigma) as previously described $[3,43]$. Briefly, HC11 cells were crosslinked with $1 \%$ formaldehyde, washed $3 \times$ with cold PBS $\left(4^{\circ} \mathrm{C}\right)$, and the nuclear pellets were collected by centrifuge. Nuclear pellets were then resuspended in $300 \mu \mathrm{l}$ DNA shearing buffer containing protease inhibitor cocktail, sonicated on ice to approximately 200 1000 bp (verified by standard agarose gel analysis), centrifuged at $14000 \mathrm{rpm}$ for 10 minutes to pellet cell debris and the supernatants were collected and diluted 1:1 in dilution buffer and used for DNA immunoprecipitation. $10 \mathrm{ul}$ diluted supernatant was used as input control. One $\mu \mathrm{g}$ of Myc or Miz1 specific IgG immunoprecipitated proteinDNA complexes were isolated and protein-DNA crosslinks reversed $\left(65^{\circ} \mathrm{C}, 2\right.$ hours). After purification, immunoprecipitated DNA was analyzed by PCR using primers specific for proximal and distal mouse C/EBP $\delta$ promoter [60]. Primer sequences are as follows: P200 (region -226 to -24 of the mouse $\mathrm{C} / \mathrm{EBP} \delta$ promoter containing STAT3 and SP1 binding sites), 5'-GCGTGTCGGGGCCAAATCCA-3'(forward primer), 5'-TTTCTAGCCCCAGCTGACGCGC-3'(reverse primer); P1.8K (region -1856 to -1676 of the promoter) as control, 5'-TGCTTCTATGGCATCCAG-3'(forward primer), 5'-GAGGGGCTGTGGAATATT-3'(reverse primer).

\section{Miz1 protein purification}

Full length Miz1 cDNA was cloned into pGEX-4T-1 vector (Miz1-GST). The Miz1-GST plasmid was transformed to BL21 (DE3) competent cell (Stratagene). The Miz1-GST protein was purified by affinity binding using Glutathione sepharose beads (GE Healthcare) following the manufacturer's protocol. Miz1 protein was confirmed by western blot with detection using Miz1 and GST antibodies (Santa Cruz, Biotechnology).

\section{Electromobility Shift Assay (EMSA)}

DNA probes (a to g) were generated by PCR using mouse $\mathrm{C} / \mathrm{EBP} \delta$ promoter (1.7 kb fragment) as template. Primer sequences are available upon request. Double stranded oligos used to produce Probes h, j, and i were purchased (Sigma). Probes used in EMSA reactions were 5 endlabeled with 6-FAM (6-Carboxyfluorescein, Sigma). EMSAs were performed by incubating labeled probes $(20$ ng) with purified Miz1 protein in binding buffer $(10 \mathrm{mM}$ Tris pH 7.9, $4 \mathrm{mM} \mathrm{MgCl}$, $5 \%$ glycerol, $0.1 \mathrm{mM} \mathrm{DTT,} 20$ $\mathrm{ng} / \mu \mathrm{l}$ poly $(\mathrm{dI}: \mathrm{dC})$ and $0.2 \% \mathrm{NP}-40$ ) for one hour at room temperature. To perform EMSA competition assays unla- belled probes were pre-incubated with Miz1 in binding buffer for $10 \mathrm{~min}$ prior to addition of the labeled probe. The concentration of unlabeled probes used was 5-25fold molar excess over labeled probe. Following incubation, samples were loaded onto a $4.5 \%$ native acrylamide gel (pre-run for one hour) and electrophoresed for one hour at $100 \mathrm{~V}$. Gels were scanned using the Typhoon 9410 imager (GE healthcare).

\section{List of abbreviations}

C/EBPS: CCAAT/Enhancer Binding Protein\&; ChIP: Chromatin Immunoprecipitation; MECs: Mammary epithelial cells; SAGE: Serial Analysis of Gene Expression; Inr: initiator element; EMSA: electromobility shift assay; Miz1: Miz1 (Myc-interacting zinc-finger protein 1); Max: Myc Associated protein X; CREB: cyclic AMP response element-binding; Dnmt3a: DNA Methyltransferase3a.

\section{Competing interests}

The authors declare that they have no competing interests.

\section{Authors' contributions}

All authors contributed to the experimental design, data interpretation, and manuscript development. JS, XY and $Y Z$ carried out the experiments, initial data analysis and figure design and optimization. JD advised on all experimental design aspects, data interpretation and final manuscript form. All authors have read and approve of the contents of this manuscript.

\section{Acknowledgements}

This work was supported by National Institutes of Health grants CA57607 (JD) and P30 CA16058. The authors thank Dr Tsonwin Hai, OSU Dept of Molecular and Cellular Biochemistry for the generous gift of the HEPG2 cells.

\section{Author Details}

1 Department of Veterinary Biosciences, Ohio State University College of Veterinary Medicine, Columbus Ohio, 43210, USA and 2 OSU Comprehensive Cancer Center, 1925 Coffey Road, Columbus Ohio, 43210, USA

Received: 1 September 2009 Accepted: 28 April 2010

Published: 28 April 2010

\section{References}

1. Ramji DP, Foka P:CCAAT/enhancer-binding proteins: structure, function and regulation. Biochem J 2002, 365:561-575.

2. Johnson PF: Molecular stop signs: regulation of cell-cycle arrest by C/ EBP transcription factors. J Cell Sci 2005, 118:2545-2555.

3. Zhang Y, Liu T, Yan P, Huang T, Dewille J: Identification and characterization of CCAAT/Enhancer Binding proteindelta (C/EBPdelta) target genes in $\mathrm{GO}$ growth arrested mammary epithelial cells. BMC Mol Biol 2008, 9:83.

4. O'Rourke J, Yuan R, DeWille J: CCAAT/enhancer-binding protein-delta (C/EBP-delta) is induced in growth-arrested mouse mammary epithelial cells. J Biol Chem 1997, 272:6291-6296.

5. O'Rourke JP, Newbound GC, Hutt JA, DeWille J: CCAAT/enhancerbinding protein delta regulates mammary epithelial cell G0 growth arrest and apoptosis. J Biol Chem 1999, 274:16582-16589.

6. O'Rourke JP, Hutt JA, DeWille J: Transcriptional regulation of C/EBPdelta in $\mathrm{G}(0)$ growth-arrested mouse mammary epithelial cells. Biochem Biophys Res Commun 1999, 262:696-701.

7. Hutt JA, O'Rourke JP, DeWille J: Signal transducer and activator of transcription 3 activates CCAAT enhancer-binding protein delta gene transcription in G0 growth-arrested mouse mammary epithelial cells and in involuting mouse mammary gland. J Biol Chem 2000, 275:29123-29131 
8. Hutt JA, DeWille JW: Oncostatin M induces growth arrest of mammary epithelium via a CCAAT/enhancer-binding protein delta-dependent pathway. Mol Cancer Ther 2002, 1:601-610.

9. Sivko GS, DeWille JW: CCAAT/Enhancer binding protein delta (c/ EBPdelta) regulation and expression in human mammary epithelial cells: I. "Loss of function" alterations in the c/EBPdelta growth inhibitory pathway in breast cancer cell lines. J Cell Biochem 2004, 93:830-843

10. Sivko GS, Sanford DC, Dearth LD, Tang D, DeWille JW: CCAAT/Enhancer binding protein delta (C/EBPdelta) regulation and expression in human mammary epithelial cells: II. Analysis of activating signal transduction pathways, transcriptional, post-transcriptional, and post-translational control. J Cell Biochem 2004, 93:844-856

11. Tang D, Sivko GS, Dewille JW: Promoter methylation reduces C/EBPdelta (CEBPD) gene expression in the SUM-52PE human breast cancer cell line and in primary breast tumors. Breast Cancer Res Treat 2005:1-10.

12. Gery S, Tanosaki S, Hofmann WK, Koppel A, Koeffler HP: C/EBPdelta expression in a BCR-ABL-positive cell line induces growth arrest and myeloid differentiation. Oncogene 2005, 24:1589-1597.

13. Ikezoe T, Gery S, Yin D, O'Kelly J, Binderup L, Lemp N, Taguchi H, Koeffler HP: CCAAT/enhancer-binding protein delta: a molecular target of 1,25dihydroxyvitamin D3 in androgen-responsive prostate cancer LNCaP cells. Cancer Res 2005, 65:4762-4768.

14. Huang AM, Montagna C, Sharan S, Ni Y, Ried T, Sterneck E: Loss of CCAAT/ enhancer binding protein delta promotes chromosomal instability. Oncogene 2004, 23:1549-1557.

15. Gigliotti AP, Johnson PF, Sterneck E, DeWille JW: Nulliparous CCAAT/ enhancer binding proteindelta (C/EBPdelta) knockout mice exhibit mammary gland ductal hyperlasia. Exp Biol Med (Maywood) 2003, 228:278-285.

16. Porter D, Lahti-Domenici J, Keshaviah A, Bae YK, Argani P, Marks J, Richardson A, Cooper A, Strausberg R, Riggins GJ, et al:: Molecular markers in ductal carcinoma in situ of the breast. MolCancer Res 2003, 1:362-375.

17. Porter DA, Krop IE, Nasser S, Sgroi D, Kaelin CM, Marks JR, Riggins G, Polyak K: A SAGE (serial analysis of gene expression) view of breast tumor progression. Cancer Res 2001, 61:5697-5702.

18. LaTulippe E, Satagopan J, Smith A, Scher H, Scardino P, Reuter V, Gerald $W L$ : Comprehensive gene expression analysis of prostate cancer reveals distinct transcriptional programs associated with metastatic disease. Cancer Res 2002, 62:4499-4506.

19. Kuramoto T, Morimura K, Yamashita S, Okochi E, Watanabe N, Ohta T, Ohki M, Fukushima S, Sugimura T, Ushijima T: Etiology-specific gene expression profiles in rat mammary carcinomas. Cancer Res 2002, 62:3592-3597.

20. Dearth $L R$, Hutt J, Sattler A, Gigliotti A, DeWille J: Expression and function of CCAAT/enhancer binding proteinbeta (C/EBPbeta) LAP and LIP isoforms in mouse mammary gland, tumors and cultured mammary epithelial cells. J Cell Biochem 2001, 82:357-370.

21. Ko CY, Hsu HC, Shen MR, Chang WC, Wang JM: Epigenetic silencing of CCAAT/enhancer-binding protein delta activity by YY1/polycomb group/DNA methyltransferase complex. J Biol Chem 2008, 283:30919-30932

22. Agrawal S, Hofmann WK, Tidow N, Ehrich M, Boom D van den, Koschmieder S, Berdel WE, Serve H, Muller-Tidow C: The C/EBPdelta tumor suppressor is silenced by hypermethylation in acute myeloid leukemia. Blood 2007, 109:3895-3905.

23. Vegesna V, Takeuchi S, Hofmann WK, Ikezoe T, Tavor S, Krug U, Fermin AC, Heaney A, Miller CW, Koeffler HP: C/EBP-beta, C/EBP-delta, PU.1, AML1 genes: mutational analysis in 381 samples of hematopoietic and solid malignancies. Leuk Res 2002, 26:451-457.

24. Tang D, DeWille J: Detection of base sequence changes in the CEBPD gene in human breast cancer cell lines and primary breast cancer isolates. Mol Cell Probes 2003, 17:11-14.

25. Adhikary S, Eilers M: Transcriptional regulation and transformation by Myc proteins. Nat Rev Mol Cell Biol 2005, 6:635-645.

26. Chen Y, Olopade OI: MYC in breast tumor progression. Expert Rev Anticancer Ther 2008, 8:1689-1698.

27. Hynes NE, Lane HA: Myc and mammary cancer: Myc is a downstream effector of the ErbB2 receptor tyrosine kinase. J Mammary Gland Biol Neoplasia 2001, 6:141-150.
28. Gartel AL, Shchors K: Mechanisms of c-myc-mediated transcriptional repression of growth arrest genes. Exp Cell Res 2003, 283:17-21.

29. Amundson SA, Zhan Q, Penn LZ, Fornace AJ Jr: Myc suppresses induction of the growth arrest genes gadd 34 , gadd 45 , and gadd 153 by DNA-damaging agents. Oncogene 1998, 17:2149-2154.

30. Barsyte-Lovejoy D, Mao DY, Penn LZ: c-Myc represses the proximal promoters of GADD45a and GADD153 by a post-RNA polymerase II recruitment mechanism. Oncogene 2004, 23:3481-3486.

31. Claassen GF, Hann SR: A role for transcriptional repression of p21CIP1 by c-Myc in overcoming transforming growth factor beta -induced cell-cycle arrest. Proc Natl Acad Sci USA 2000, 97:9498-9503.

32. Conzen SD, Gottlob K, Kandel ES, Khanduri P, Wagner AJ, O'Leary M, Hay $\mathrm{N}$ : Induction of cell cycle progression and acceleration of apoptosis are two separable functions of c-Myc: transrepression correlates with acceleration of apoptosis. Mol Cell Biol 2000, 20:6008-6018.

33. Feng $X H$, Liang $Y Y$, Liang $M, Z$ hai $W$, Lin $X$ : Direct interaction of c-Myc with Smad2 and Smad3 to inhibit TGF-beta-mediated induction of the CDK inhibitor p15(Ink4B). Mol Cell 2002, 9:133-143.

34. Wanzel M, Herold S, Eilers M: Transcriptional repression by Myc. Trends Cell Biol 2003, 13:146-150.

35. Lee TC, Li L, Philipson L, Ziff EB: Myc represses transcription of the growth arrest gene gas1. Proc Natl Acad Sci USA 1997, 94:12886-12891.

36. Marhin WW, Chen S, Facchini LM, Fornace AJ Jr, Penn LZ: Myc represses the growth arrest gene gadd45. Oncogene 1997, 14:2825-2834.

37. Seoane J, Le HV, Massague J: Myc suppression of the p21 (Cip1) Cdk inhibitor influences the outcome of the $\mathrm{p} 53$ response to DNA damage. Nature 2002, 419:729-734

38. Seoane J, Pouponnot C, Staller P, Schader M, Eilers M, Massague J: TGFbeta influences Myc, Miz-1 and Smad to control the CDK inhibitor p15INK4b. Nat Cell Biol 2001, 3:400-408.

39. Staller P, Peukert K, Kiermaier A, Seoane J, Lukas J, Karsunky H, Moroy T, Bartek J, Massague J, Hanel F, Eilers M: Repression of p15INK4b expression by Myc through association with Miz-1. Nat Cell Biol 2001, 3:392-399

40. Lee Y, Schwarz E, Davies M, Jo M, Gates J, Wu J, Zhang X, Lieberman JR Differences in the cytokine profiles associated with prostate cancer cell induced osteoblastic and osteolytic lesions in bone. J Orthop Res 2003, 21:62-72.

41. Yang W, Shen J, Wu M, Arsura M, FitzGerald M, Suldan Z, Kim DW, Hofmann CS, Pianetti S, Romieu-Mourez R, et al: Repression of transcription of the p27(Kip1) cyclin-dependent kinase inhibitor gene by c-Myc. Oncogene 2001, 20:1688-1702.

42. Antonson P, Pray MG, Jacobsson A, Xanthopoulos KG: Myc inhibits CCAAT/enhancer-binding protein alpha-gene expression in HIB-1B hibernoma cells through interactions with the core promoter region. Eur J Biochem 1995, 232:397-403.

43. Zhang Y, Sif S, Dewille J: The mouse C/EBPdelta gene promoter is regulated by STAT3 and Sp1 transcriptional activators, chromatin remodeling and c-Myc repression. J Cell Biochem 2007.

44. Kleine-Kohlbrecher D, Adhikary S, Eilers M: Mechanisms of transcriptional repression by Myc. Curr Top Microbiol Immunol 2006, 302:51-62.

45. Huber O, Menard L, Haurie V, Nicou A, Taras D, Rosenbaum J: Pontin and reptin, two related ATPases with multiple roles in cancer. Cancer Res 2008, 68:6873-6876

46. Blagosklonny MV, Pardee AB: The restriction point of the cell cycle. Cell Cycle 2002, 1:103-110

47. Roy PG, Thompson AM: Cyclin D1 and breast cancer. Breast 2006 $15: 718-727$

48. Sanford DC, DeWille JW: C/EBPdelta is a downstream mediator of IL-6 induced growth inhibition of prostate cancer cells. Prostate 2005, 63:143-154.

49. Sivko GS, Sanford DC, Dearth LD, Tang D, DeWille JW: CCAAT/enhancer binding protein delta (C/EBPdelta) regulation and expression in human mammary epithelial cells: II. Analysis of activating signal transduction pathways, transcriptional, post-transcriptional, and posttranslational control. JCell Biochem 2004, 93:844-856.

50. Ziegelbauer J, Shan B, Yager D, Larabell C, Hoffmann B, Tjian R: Transcription factor MIZ-1 is regulated via microtubule association. Mol Cell 2001, 8:339-349

51. Hurlin PJ, Huang J: The MAX-interacting transcription factor network. Semin Cancer Biol 2006, 16:265-274. 
52. Mao DY, Watson JD, Yan PS, Barsyte-Lovejoy D, Khosravi F, Wong WW, Farnham PJ, Huang TH, Penn LZ: Analysis of Myc bound loci identified by CpG island arrays shows that Max is essential for Myc-dependent repression. Curr Biol 2003, 13:882-886.

53. Ponzielli R, Katz S, Barsyte-Lovejoy D, Penn LZ: Cancer therapeutics: targeting the dark side of Myc. Eur J Cancer 2005, 41:2485-2501.

54. Cantwell CA, Sterneck E, Johnson PF: Interleukin-6-specific activation of the C/EBPdelta gene in hepatocytes is mediated by Stat 3 and Sp1. Mol Cell Biol 1998, 18:2108-2117.

55. Wood MA, McMahon SB, Cole MD: An ATPase/helicase complex is an essential cofactor for oncogenic transformation by c-Myc. Mol Cell 2000, 5:321-330

56. Gallant P: Control of transcription by Pontin and Reptin. Trends Cell Biol 2007, 17:187-192.

57. Jha S, Dutta A: RVB1/RVB2: running rings around molecular biology. Mol Cell 2009, 34:521-533.

58. Etard C, Gradl D, Kunz M, Eilers M, Wedlich D: Pontin and Reptin regulate cell proliferation in early Xenopus embryos in collaboration with c-Myc and Miz-1. Mech Dev 2005, 122:545-556.

59. Brenner C, Deplus R, Didelot C, Loriot A, Vire E, De Smet C, Gutierrez A, Danovi D, Bernard D, Boon T, et al:: Myc represses transcription through recruitment of DNA methyltransferase corepressor. Embo J 2005, 24:336-346.

60. Zhang Y, Sif S, Dewille J: The mouse C/EBPdelta gene promoter is regulated by STAT3 and Sp1 transcriptional activators, chromatin remodeling and c-Myc repression. J Cell Biochem 2007, 102:1256-1270

61. Zhou S, Dewille JW: Proteasome-mediated CCAAT/enhancer-binding protein delta (C/EBPdelta) degradation is ubiquitin-independent. Biochem J 2007, 405:341-349.

62. Zhou S, Si J, Liu T, DeWille JW: PIASy represses CCAAT/enhancer-binding protein delta (C/EBPdelta) transcriptional activity by sequestering C/ EBPdelta to the nuclear periphery. J Biol Chem 2008, 283:20137-20148.

doi: $10.1186 / 1476-4598-9-92$

Cite this article as: Si et al., Myc interacts with Max and Miz1 to repress C/ EBP? promoter activity and gene expression Molecular Cancer 2010, 9:92 